\title{
Design and Development of a Heat Pump Based Moisture Control System for Industrial Drying of Medicinal Plants
}

\author{
E.M.A.C. Ekanayake ${ }^{*}$, K.S.P. Amaratunge ${ }^{1}$, H.K.P.P. Kariyawasam ${ }^{1}$, M.G.M. Kumara ${ }^{1}$ and \\ H.L.A.P.G.I.L. Bandara ${ }^{1}$
}

Postgraduates Institute of Agriculture

University of Peradeniya

Peradeniya

\begin{abstract}
Moisture control is one of the most common preservation methods used for enhancing the shelf life of agricultural produce. When processing or storing of fresh produce, a special attention has to be given in maintaining low temperature of the drying air. A heat pump based dehumidifier, which comprised of an evaporator, condenser, compressor, expansion device, a control unit, main frame and a covering chamber, was designed and fabricated for moisture control of agricultural produce. The air with high relative humidity coming from the evaporator was passed through the condenser unit and reheated up to $30{ }^{\circ} \mathrm{C}$. The control unit was designed using Arduino controller to maintain preferable relative humidity in the storage room with minimum working cycle. Duty cycle of the system was 20 minutes 'switch on' and 5 minutes 'switch off' time. The performance of the heat pump based dehumidifier system was evaluated by studying the temperature and relative humidity of empty store room and with stored Gotukola (Centella asiatica). The relative humidity of the empty store room was found to be reduced from 50\% to $16 \%$ within 6 hours of operation of heat pump dehumidifier. It was also possible to reduce the moisture content of fresh Gotukola from 88\% to 12\% within 27 hours. During this period the air temperature of the storeroom varied from $25^{\circ} \mathrm{C}$ to $44{ }^{\circ} \mathrm{C}$. The specific moisture extraction rate of the heat pump dehumidifier system was $0.49 \mathrm{~kg} / \mathrm{kWh}$. The designed and developed heat pump based moisture control system performed satisfactorily and could be effectively used in moisture control of medicinal plants.
\end{abstract}

Keywords: Dehumidifying, heat pump, moisture control

\section{INTRODUCTION}

Moisture control is the most common method of medicinal plant preservation and it carries a substantial expense in medicinal plant production due to high investment and energy costs. Preservation of medicinal properties and consequent earnings are significantly influenced by the drying regime. Low drying temperatures between $30{ }^{\circ} \mathrm{C}$ and $50{ }^{\circ} \mathrm{C}$ are recommended to protect sensitive active ingredients, but the decelerated drying process causes a low capacity of drying installations (Müller and Heindl, 2006). The rate of development of microorganisms and the enzyme activity are comparatively low when the medicinal plant

\footnotetext{
Department of Agricultural Engineering, Faculty of Agriculture, University of Peradeniya, Sri Lanka

* Corresponding author: asankaem18@gmail.com
} 


\section{Design and Development of a Heat Pump Based Moisture Control System}

parts are stored at relative humidity below $60 \%$ and it is suitable for preservation of medicinal quality of plants and plant parts (Heiss and Echner, 1990).

Heat pump technology has been successfully used for drying agricultural products as well as for other domestic dehumidification/heating applications. Heat pump drying has been found to be very effective in drying of material with higher amount of free moisture such as tomato (Sosle, 2002). A comprehensive review article on principles and potentials of heat pump drying of fruits and vegetables applicable for Sub-Saharan Africa have been documented by Fayose and Huan in 2016. Heat pump dehumidification system can provide both controllable environment for better product quality at low energy consumption (Bonazzi \& Dumoulin 2011). The dryer performance can be defined according to its capacity or energy effectiveness. The dryer capacity refers to the moisture extraction rate (Kilogram of moisture removed per hour). Effectiveness of a dryer system is accessed based on the Specific Moisture Extraction Rate (SMER, kilogram of moisture removed per kilowatt-hour) (Prasertsan and Saen-Saby, 1998). Drying efficiency of heat pump drying system is around 95\% with SMER is 1 to 4 and the operating temperature and relative humidity ranges from 10 to $80{ }^{\circ} \mathrm{C}$ and 10 to $80 \%$ respectively (Jangam and Visavale, 2014). Also the operating cost is relatively low compared to the other drying methods of hot air, vacuum and freeze drying. The basic considerations of moisture control in food industry are quality improvement, economic and environmental concerns, and heat pump drying system capable of fulfilling all three concerns (Fayose and Huan, 2016). Therefore, this study was conducted to design and fabricate a heat pump dehumidifier (HPD) system as an alternate method of moisture control in several herbs. Specifically, this system will be used to change the relative humidity inside the storage within shorter period and allows the raw material to reach the equilibrium moisture with environment. This process will enable final product with uniform quality. Also, it will be easier to maintain the required temperature, humidity, air flow rate and the retention time to get a better quality product.

\section{MATERIALS AND METHODS}

HPD system was designed and fabricated for moisture control of medicinal plants. The volatile substances in medicinal plants tend to vaporize when kept or processed at higher temperatures. When processing or storing of medicinal plants or plant parts, a special attention has to be given in maintaining low temperatures. The objective of this moisture control system is to convert high moist ambient air to air with low moisture while maintaining relatively low temperature.

\section{Fabrication of heat pump dehumidifier system}

The HPD system consists of evaporator, condenser, compressor, expansion device, a controlling unit, main frame and covering chamber. Figure 1 shows the HPD with air flow directions and Figure 2 shows detailed view of the HPD unit. The Main frame of HPD system was fabricated using metal box bars and used to attach all components of HPD system. Two wheels were fixed to move the whole system. Split type air conditioner evaporator was used as evaporator unit of HPD system that reduces the moisture content of air entering. Split type air conditioner condenser was used as the condenser unit of HPD system. Air coming from the evaporator unit is flown through the condenser unit and heated by absorbing heat energy from the refrigerant of the condenser. 
The conditioned low moist air temperature was around $30{ }^{\circ} \mathrm{C}$. The chamber and louvers were made out of iron plates in such a way that the air flow occurs directly from the evaporator to the condenser unit.

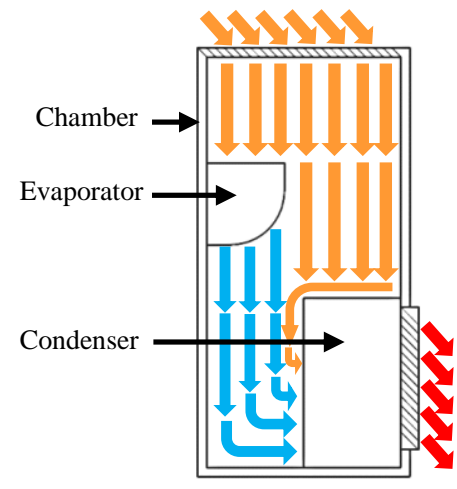

Air with high relative humidity (ambient air)

Saturated air at low temperature

Air with low relative humidity

Figure 1. Air flow through the HPD system

\section{Control unit of the HPD System}
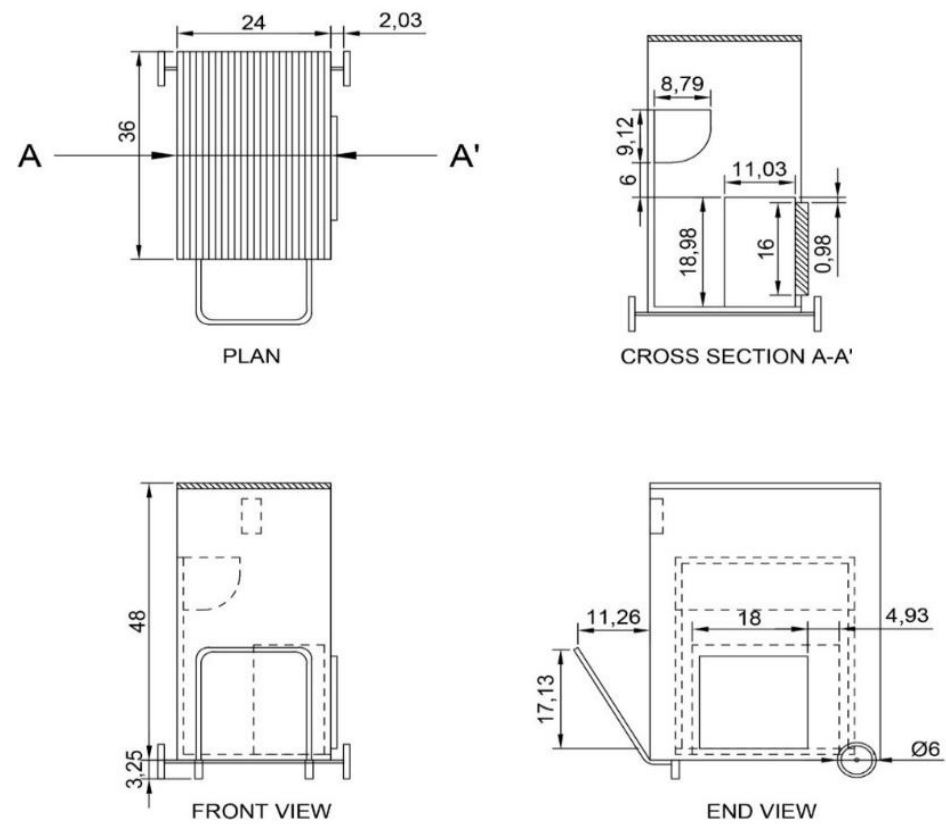

Figure 2. Detailed-view of HPD system 
The control unit was designed to maintain preferable relative humidity $(\mathrm{RH})$ level in the storage room with minimum working cycle of HPD systems (Figure 3). This control unit was connected to the HPD system to control the 'on' time of HPD system. Control unit was designed using Arduino (Genuino Uno, Rev3) electronic circuit system and programmed using C language. Sensor (AM2320, Aosong, China) was used as RH sensor and potentiometer was connected to set preferable RH level in the store room. A solid state relay was used for the power control of the HPD system. Duty cycle of the HPD system (Figure 4) was designed, 20 minutes for switch on time and 5 minutes for switch off time. The application of duty cycle will lead to a safer operation of HPD system. It checks the RH before switch on the system, if only RH > set value system will switch on.

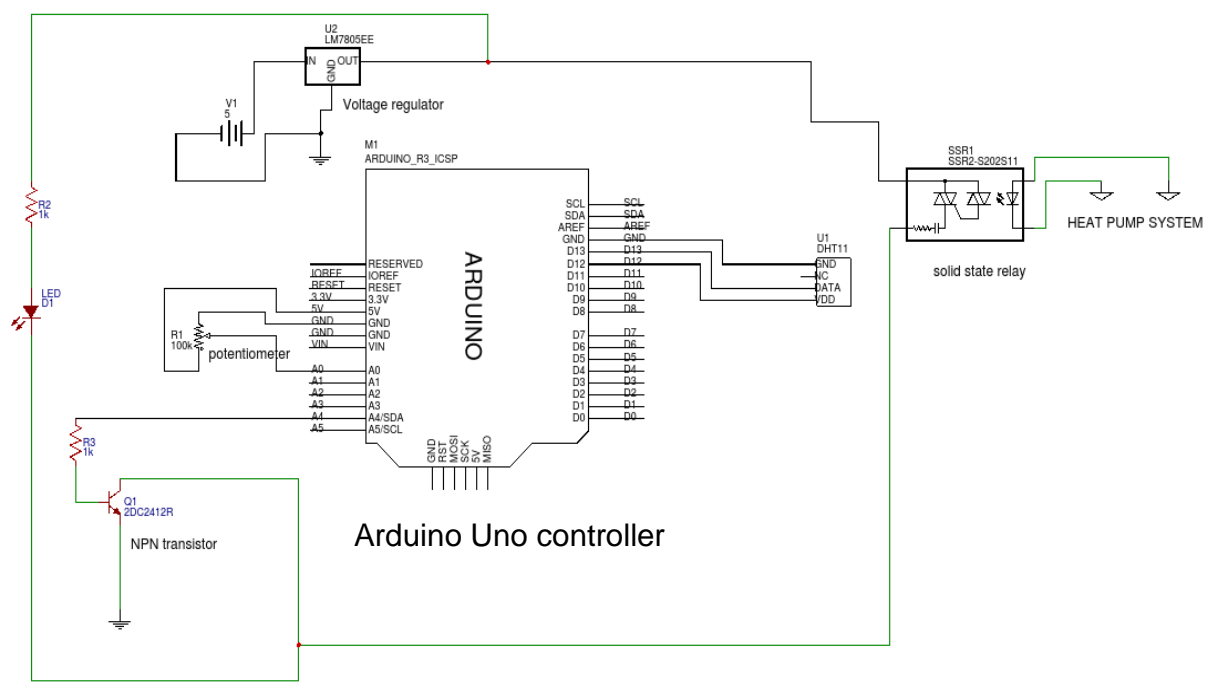

Figure 3. Schematic diagram of control unit circuit

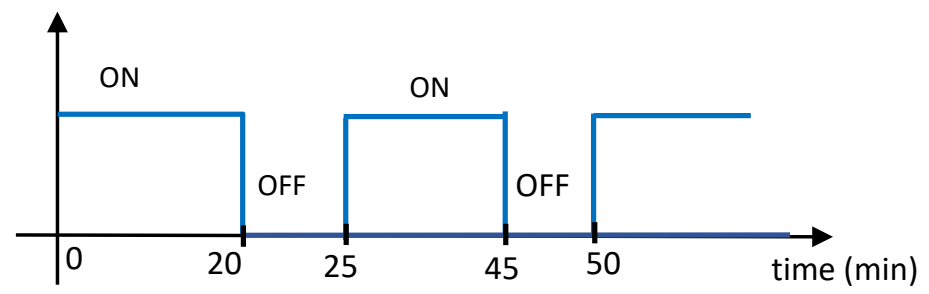

Figure 4. Duty cycle of the HPD system

\section{Evaluation of HPD system}

The current and voltage consumed by the HPD system were measured using a clip-on meter. The energy consumption of the HPD system was calculated and converted to $\mathrm{kWh}(1 \mathrm{~kW}=$ $\left.3.6 \times 10^{6} \mathrm{~J}\right)$.

$$
\begin{aligned}
& P=V I \operatorname{Cos} \theta \\
& P=V I \operatorname{Cos} \Phi
\end{aligned}
$$




$$
\begin{aligned}
& E=P t \\
& \text { Energy input to the system }(k W h)=\frac{E}{3.6 \times 10^{6}}
\end{aligned}
$$

Where power, P $(W)$; energy, $E(J)$; voltage, $V(V)$; current, $I(A)$; time, $T(s)$; $\operatorname{Cos} \theta(0.8)$

The condensed water from the HPD system was collected into the measuring can for an hour while the system was working. The specific moisture removal rate (SMER) was calculated using the equation 5 (Fayose and Huan 2016). It is assumed that the amount of water evaporated from the drying room is equal to collected water during unit time period.

$$
S M E R=\frac{\text { Amount of } \text { water removed by the system }(\mathrm{kg})}{\text { Energy input to the system }(\mathrm{kWh})}
$$

\section{Measurement of relative humidity and temperature}

Temperature was measured using sensor (DHT 11, Aosong, China) and a digital RH \& thermometer. The sensor and digital RH \& thermometer were kept inside the storage room with HPD system and readings were taken at 3 hour intervals.

\section{Measurement of the moisture content of medicinal plants}

After measuring the initial moisture content of medicinal plants or plant parts, samples were kept in the bin (Figure 5). Samples inside the bin were ventilated using a fan which is fixed to the bottom of the bin. Bin was kept on the top electronic loading balance to measure the weight reduction at three hours' interval. Samples were taken from the top layer and the bottom layer of the bin at three hours' interval for moisture determination. Moisture determination was done by air oven dry method by drying Gotukola (Centella asiatica) samples at $100-105{ }^{\circ} \mathrm{C}$ for two consecutive weight measurements (with $\pm 5 \mathrm{mg}$ ). Moisture determination was done with the use of weight reduction method.

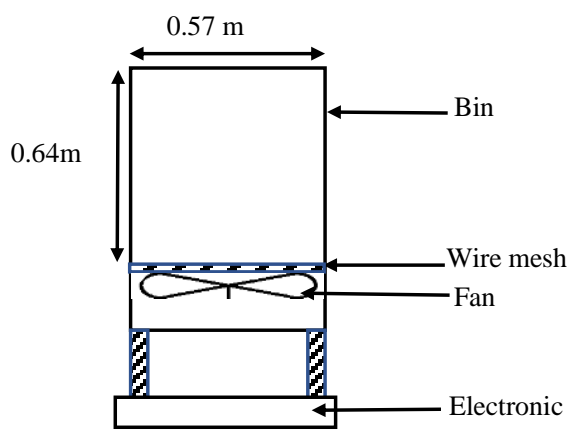

Figure 5. Schematic diagram of the bin 


\section{Design and Development of a Heat Pump Based Moisture Control System}

\section{RESULTS AND DISCUSSION}

The designed and fabricated HPD system was tested for its performance in a storage room. Metal container $(5.919 \mathrm{~m} \times 2.340 \mathrm{~m} \times 2.380 \mathrm{~m})$ was used as the storage room. The temperature and $\mathrm{RH}$ variations inside the empty storage room and with stored medicinal plants were evaluated with time. The moisture content of medicinal plants and water removed by the HPD system were also analysed over the time for the evaluation of the HPD. The Figure 6 shows the RH and temperature variations in the empty storage room. RH and temperature were monitored for 24 hours starting from $15.00 \mathrm{~h}$ in the evening. The initial $\mathrm{RH}$ was around $50 \%$, but with the operation of HPD system RH was reduced to $16 \%$ within 6 hours. For the remaining 18 hours, there was no considerable change in RH. With the operation of HPD system minimum RH of $13 \%$ was achieved. The temperature of the empty store room decreased from $38{ }^{\circ} \mathrm{C}$ to $30{ }^{\circ} \mathrm{C}$ within first 6 hours because of the lower ambient temperature during the evening. After first 15 hours the temperature increased because of the heat absorption during the day time. Since the absolute humidity was very low, store room could not reach to the dew point of the ambient air. The drying characteristics of fresh Gotukola were tested for the evaluation of HPD system. A sample of $13 \mathrm{~kg}$ Gotukola was used for this evaluation. Figure 7 shows the RH and temperature variation in the storage room with stored Gotukola. RH and temperature were recorded at 3 hour intervals. After 3 hours of operation of the HPD system, the RH of the store room decreased from $90 \%$ to $68 \%$ and remained fairly constant for 6 hours while water condensation continued further. This is due to the evaporation of moisture from the Gotukola.

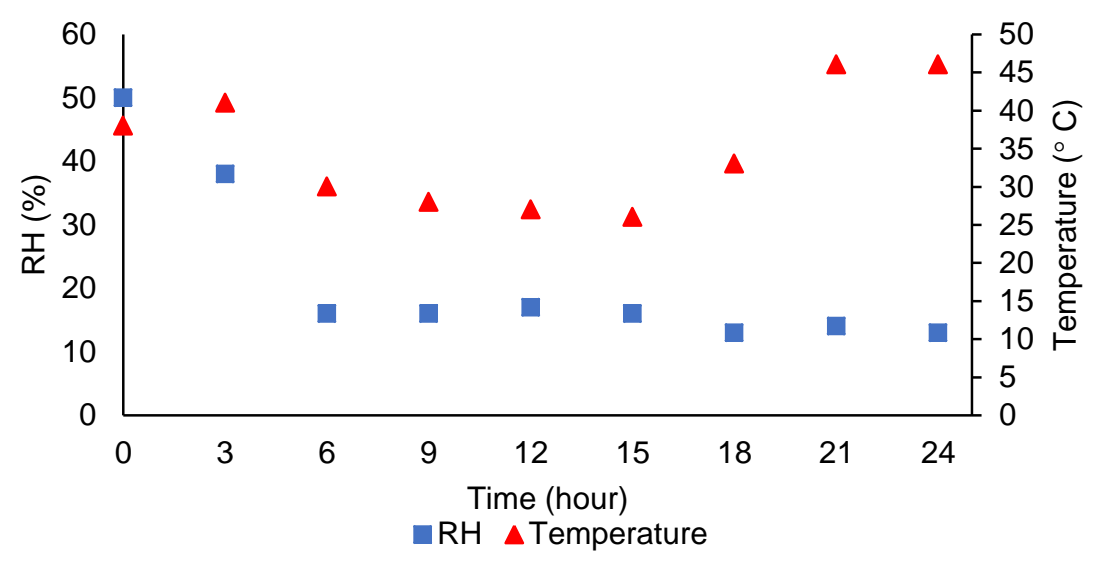

Figure 6. RH and temperature variation with time in the empty storage room

The RH decreased to $46 \%$ inside the store room within next 3 hours and the reason could be the resistance to moisture removal once the free moisture is evaporated from the stored materials. Initial inside-storage-temperature was $30{ }^{\circ} \mathrm{C}$. Temperature was decreased to $25^{\circ} \mathrm{C}$ within first 12 hours, because of heat removal from the storage room to the environment at night. During the day time the storage metal container got heated up due to direct sunlight and the temperature of the store increased up to $44{ }^{\circ} \mathrm{C}$. High temperature leads to evaporate more moisture from Gotukola. Therefore, $\mathrm{RH}$ also increased from $63 \%$ to $80 \%$ while the temperature was increasing. After 21 hours of operation, the temperature decreased from 44 
${ }^{\circ} \mathrm{C}$ to $29^{\circ} \mathrm{C}$ during the night time. This night time temperature fall must accompany a rise of $\mathrm{RH}$, but with the operation of HPD system the $\mathrm{RH}$ was reduced due to moisture condensation.

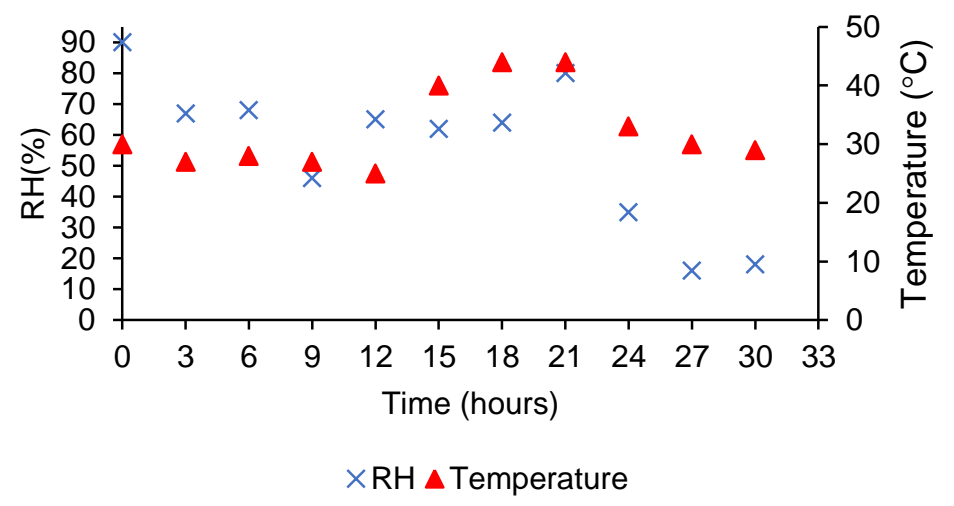

Figure 7. RH and temperature variation with time in the Gotukola stored room

The moisture content of the top and bottom layers of the sample bed of Gotukola was measured with time (Figure 8). The initial moisture content of Gotukola was $88 \%$ w.b. The moisture content of Gotukola reached to a constant moisture of $12 \%$ w.b. after 30 hours of HPD drying. But the industrial moisture requirement of Gotukola is below 10\% w.b., therefore a supplementary heat source will be required to bring down moisture content to the industrial requirement. Normally in industry, Gotukola is dried by hot air drier at $70{ }^{\circ} \mathrm{C}$. But it could be dried within 30 hours at comparatively low temperature with this method while preserving its natural colour and volatile componds.

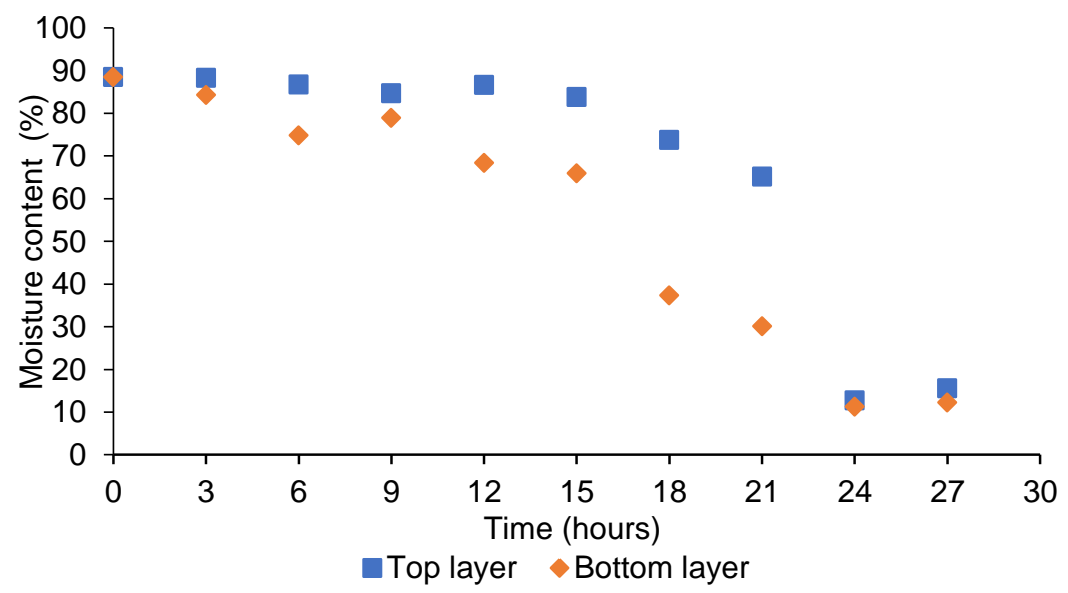

Figure 8. Moisture content of Gotukola (Centella asiatica) with time 
The duty cycle of HPD system is 20 minutes on time and 5 minutes off time. Current usage of HPD system is shown in (Table 1). The evaporated water from dehumidifier was collected and recorded with time (Table 2).

Table 1. The current usage by the system

\begin{tabular}{cccc}
\hline Time $(\min )$ & Status of machine & Current $(\mathrm{A})$ & Voltage $(\mathrm{V})$ \\
\hline 20 & On & 5.0 & 230 \\
05 & Off & 0 & 230 \\
\hline
\end{tabular}

Table 2. RH, temperature and condensed water by HPD system with time

\begin{tabular}{cccc}
\hline Time (hours) & $\begin{array}{c}\text { RH } \\
(\%)\end{array}$ & $\begin{array}{c}\text { Temperature } \\
\left({ }^{\circ} \mathrm{C}\right)\end{array}$ & $\begin{array}{c}\text { Collected water } \\
\text { (Cumulative) } \\
(\mathrm{mL})\end{array}$ \\
\hline 3 & 67 & 27 & 2000 \\
6 & 68 & 28 & 3450 \\
9 & 46 & 27 & 5950 \\
12 & 65 & 25 & 8200 \\
15 & 62 & 40 & 10300 \\
18 & 64 & 44 & 10350 \\
21 & 80 & 44 & 12200 \\
24 & 35 & 33 & 14350 \\
27 & 16 & 30 & 15980 \\
30 & 18 & 29 & 17080 \\
\hline
\end{tabular}

Energy consumption per cycle of HPD system was $0.3067 \mathrm{kWh}$ and energy consumption of fan for $30 \mathrm{~h}$ was $0.9 \mathrm{kWh}$. Total time per cycle was 25 minutes. Therefore, HPD system operated 2.4 cycles per hour. Hence energy consumption of HPD system per hour was 0.736 $\mathrm{kWh}$. The weight of water removed from $13 \mathrm{~kg}$ of Gotukola was $11.2 \mathrm{~kg}$. SMER value calculated for $30 \mathrm{~h}$ period was $0.49 \mathrm{~kg} / \mathrm{kWh}$.

\section{CONCLUSIONS}

SMER for the HPD system was $0.49 \mathrm{~kg} / \mathrm{kWh}$. Normally SMER values in heat pumps vary between $1.0-4.0$ (Aceves-Saborio, 1993). The lower SMER value for the study was due to the small volume of material used compared to the storage size. However, the experimental samples showed a satisfactory level of drying and it was possible to reduce the moisture content of Gotukola from $88 \%$ to $12 \%$ within 27 hours. Therefore, it can be concluded that the established heat pump based moisture control system could be effectively used in moisture controlling of plant materials in industrial scale.

\section{REFERENCES}

Aceves-Saborio, S. (1993). Analysis of energy consumption in heat pump and conventional driers. Heat Recov. Syst. CHP 13(5), 419-428. 
Bonazzi, C. and Dumoulin, E. (2011). Quality changes in food materials as influenced by drying processes, in modern drying technology: modern drying technology. Product Quality and Formulation, 3, 1-20.

Fayose, F. and Zhongjie, H.U.A.N. (2016). Heat pump drying of fruits and vegetables: principles and potentials for sub-Saharan Africa. Annals of the Faculty of Engineering Hunedoara-International Journal of Engineering, 14(1), 207-214.

Heiss, R. and Eichner, K. (1990). Food Preservation: Chemical, Physical and Microbiological Basis of the Procedures. Springer Publishing House, Berlin.

Jangam, S.V., Visavale, G.L. and Mujumdar, A.S. (2011). Use of renewable source of energy for drying of FVF. Drying of Foods, Vegetables and Fruits 3, 103-126.

Müller, J.O.A. C.H.I.M. and Heindl, A.L.B.E.R.T. (2006). Drying of medicinal plants. Frontis, 17, 237-252.

Prasertsan, S. and Saen-saby, P. (1998). Heat pump drying of agricultural materials. Dry. Technol. 16(1-2), 235-250.

Sosle, V. (2002). A heat pump dehumidifier assisted dryer for agri-foods. In Ph.D. dissertation, McGill University, Ontario. 